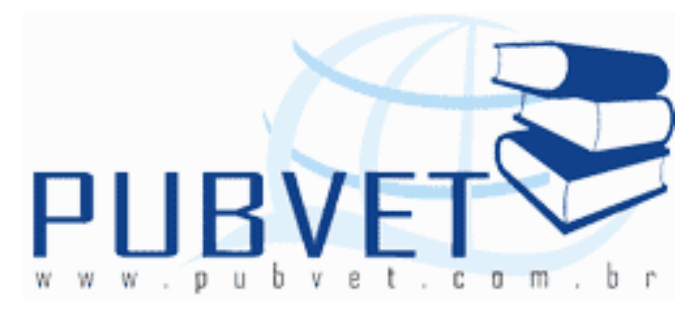

PUBVET, Publicações em Medicina Veterinária e Zootecnia.

\title{
Avaliação do grau de conformidade na aplicação de agrotóxicos em uma propriedade produtora de café em Monte Carmelo no ano de 2011
}

\author{
Antônio Leonardo Lacerra e MSc. Cláudio Costa
}

\section{Resumo}

A cafeicultura tem uma grande importância no agronegócio e no desenvolvimento sócio-econômico no Brasil. O que faz com que seja muito importante cuidar bem e saber usar os produtos na produção dos grãos. $O$ trabalho fará uma avaliação do grau de conformidade na aplicação de agrotóxicos em uma propriedade produtora de café em Monte Carmelo no ano de 2011. O objetivo principal dos agrotóxicos é combater pragas e doenças nas plantações. A utilização do mesmo deve ser de forma segura, de maneira que garanta uma boa produtividade e aumento na lucratividade instantaneamente, sem que afete a saúde dos consumidores e aplicadores. Os resultados mostram alguns pontos com deficiência dentro das avaliações. A avaliação mostrou a não conformidade na aplicação dos agrotóxicos na propriedade.

Palavras-chave: Agrotóxico; Agronegócio; Café.

\begin{abstract}
The coffee has a great importance in agribusiness and socio-economic development in Brazil. What makes it important to take care and know how to use the products in the production of grain. The work will assess the degree of conformity in the application of pesticides in a coffee producing property in
\end{abstract}


Mount Caramel in 2011. The main purpose of pesticides is to combat pests and diseases in crops. The use of the same should be safely in a way that ensures high productivity and increased profitability instantly, without affecting the health of consumers and investors. The results show some points with disabilities in assessments. The evaluation showed non-compliance in the application of pesticides on the property.

Keywords: Pesticides, Agribusiness and Coffee

\section{INTRODUÇÃO}

O agronegócio brasileiro, especialmente a produção agropecuária, apresentou crescimento na última década (MARINO et al, 2008). A cafeicultura, segundo Netafim (2010), ainda impulsiona o desenvolvimento socioeconômico no Brasil, produzindo e distribuindo riquezas, além de ter grande capacidade geradora de empregos e de ser um importante fator de fixação de mão de obra na zona rural. No Brasil, para cada hectare de café plantado, são gerados aproximadamente 2,3 empregos diretos e, pelo menos 4 empregos indiretos.

Hoje, vivencia-se uma realidade de fragmentos de conhecimento, o homem controla ações de partes e não mais do todo. $O$ foco em conhecimento pressupõe a preocupação com a eficiência financeira, melhor performance, o objetivo de se tornar líder de mercado, o fazer mais com menos, e o ajuste a contingências quaisquer, tem forçado o homem do agronegócio a buscar informações eficazes e eficientes sobre o desenvolvimento sustentável (REDIVO, 2006).

O mundo presencia a ocorrência de profundas mudanças nos cenários políticos, econômicos e sociais. Muitos países organizaram-se em blocos, e derrubaram fronteiras comerciais, o que impõem um novo tipo de relacionamento ao mercado (LOPES et al, 2008). O advento da globalização e o processo de abertura econômica no contexto internacional provocaram importantes transformações no cenário econômico brasileiro, uma vez que as 
fronteiras nacionais desapareceram, dando lugar às chamadas fronteiras transnacionais. Esse processo implicou na reestruturação das formas produtivas nos mais diversos setores (MACHADO et al, 2006).

A gestão envolve várias partes da administração tais como, recursos humanos, finanças, gerenciamento operacional, planejamento. Segundo Machado et al (2006), a atividade rural há que se recordar que a mesma apresenta maior risco e incerteza que outros negócios, uma vez que, ao trabalhar com produção viva está sujeita a sazonalidade da produção, observância de ciclos, variações climáticas, perecibilidade, necessidades próprias de processamento e transformação das matérias-primas e influência de fatores biológicos.

Neste cenário, o agronegócio brasileiro tem se mantido firme nos últimos anos demonstrando desempenho marcante, com significativa contribuição para a balança comercial e para o Produto Interno Bruto (PIB) do país (REDIVO, 2008). O mesmo autor diz que o desenvolvimento sustentável vem a ser uma estratégia de desenvolvimento que administra todos os ativos, os recursos naturais e os recursos humanos, assim como os recursos financeiros e físicos de forma compatível com o crescimento da riqueza e do bem estar em longo prazo.

A aplicação de agrotóxicos pode ser aplicada como ciência de natureza multidisciplinar. A mesma envolve ecologia, biologia, química, física, engenharia, sociologia, economia e comércio (INSTITUTOS-UFRJ, 2011). Os tratos fitossanitários compreendem o controle e o combate das pragas e doenças que atacam o cafeeiro (SANTINATO, 2005). Segundo o mesmo autor as pragas e doenças que atacam o cafeeiro são responsáveis pela redução do desenvolvimento vegetativo e perdas na produtividade e, em determinadas condições, até a morte dos cafeeiros. Desta forma, o objetivo do trabalho foi avaliar o grau de conformidade na aplicação de agrotóxicos em uma propriedade produtora de café em Monte Carmelo - MG no ano de 2011. 


\section{CAFEICULTURA E SUA RELAÇÃo COM OS AGROTÓXICOS}

Agronegócio é uma unidade agregativa que pode ser dividida em quatro segmentos, que se referem a um conjunto de atividades vinculadas à agropecuária. O agronegócio é um aglomerado de operações, de produção e distribuição de suprimentos agrícolas, das operações de produção na fazenda e do armazenamento, processamento e distribuição dos produtos agrícolas produzidos a partir das operações ali realizadas. Este conceito procura abarcar todos os vínculos intersetoriais agrícolas. (LOURENÇO, 2008) O agronegócio tornou-se uma opção de desenvolvimento econômico para o agricultor, proporcionando-Ihe uma qualidade de vida melhor na zona rural, através da produção agrícola, evitando assim o êxodo rural. (VIEIRA, 2000).

De acordo com Bacha (2004), o Brasil possui inúmeros produtos agropecuários que possuem um significante valor estratégico em nossa economia. Um dos que se destacam é o café. Em 1727 o café foi trazido da Guiana Francesa para o Brasil pelo Sargento-Mor Francisco de Mello Palheta a pedido do governador do Maranhão e Grão Pará, que o enviara às Guianas com essa missão. Já naquela época o café possuía grande valor comercial.

Agrotóxicos, defensivos agrícolas, praguicidas ou pesticidas são substâncias químicas naturais ou sintéticas, destinadas a matar, controlar ou combater de algum modo às pragas (ZAMBRONE, 1986). Os agrotóxicos teriam como objetivo principal evitar que as culturas sejam prejudicadas pelo ataque das pragas e doenças (PESSANHA, 1982). Na produção agrícola no Brasil, o uso de agrotóxicos consiste em fator essencial para alcance dos níveis de produtividade preconizado pelos órgãos de tecnologia e pesquisa. Entretanto este uso deve ser efetuado de forma segura objetivando o melhoramento e o aumento de produção, sem comprometer a saúde dos trabalhadores e dos consumidores (POLASTRO, 2005).

O Brasil é o terceiro maior consumidor de agrotóxico no mundo. A utilização excessiva polui o solo e a água, além de deixar as pragas cada vez mais fortes, os defensivos agrícolas perdem o papel na cadeia sustentável e as 
pragas desenvolvem resistência (GEREMIA, 2011). Existe uma constituição que faz com que o empregador tenha a responsabilidade de fornecer aos trabalhadores os equipamentos adequados (EPI - Equipamento de Proteção Individual) para a proteção da saúde dos mesmos, a legislação dos agrotóxicos já especifica dois inarredáveis deveres: oferecer o equipamento adequado à proteção ao funcionário e a manutenção dos equipamentos (MACHADO, 2003). Para que se tenha eficiência do produto na redução na contaminação do aplicador, do ambiente e nos custos é necessário o domínio da tecnologia de aplicação (BAUER; PEREIRA, 2005).

A aplicação pode ser feita de várias maneiras, o agricultor é quem escolhe a que mais the é conveniente. Pode-se aplicar através de tratores, aviões ou até mesmo pelo ser humano, quando for destinar em pequenas propriedades. Normalmente estas aplicações são feitas no período da manhã ou no fim da tarde. A contaminação do Meio Ambiente por agrotóxicos é agravada devida à permanência destes por muito mais tempo que o necessário após sua ação, comprometendo a vida de várias espécies (MACEDO, 2002). A aplicação indiscriminada de agrotóxicos afeta tanto a saúde humana quanto a ecossistemas naturais. Os impactos na saúde podem atingir tanto aplicadores dos produtos, os membros da comunidade e os consumidores dos alimentos contaminados com resíduos, mas, sem dúvida, a primeira categoria é a mais afetada por estes.

Para a aplicação dos agrotóxicos é necessário que o funcionário esteja utilizando todos os Equipamentos de Segurança Individual (EPI). Caso o funcionário não esteja utilizando o equipamento corretamente pode sofrer danos à sua saúde, existem dois tipos de efeitos toxicológicos, por meio direto, através da intoxicação do trabalhador rural, e por via indireta, prejudicando a saúde do consumidor, este que pode ser o trabalhador ou não quando ingere um alimento cujo nível residual se encontra em níveis prejudiciais à saúde. (PORTO; SOARES, 2007)

A produção de alimentos para uma população em constante crescimento é, hoje, o desafio básico da agricultura, que passa necessariamente pelo 
compromisso com a utilização de procedimentos e tecnologias capazes de assegurar o respeito pela saúde humana e pelo meio ambiente, e, também, a sustentabilidade da agricultura. (BRAGA; ROMANNIELO, 2008)

Segundo a Constituição, deve ser feita a entrega das embalagens conforme as regras da Tríplice Lavagem, a devolução deve ser feita nos postos credenciados, no período de até um ano após a da data da compra, que vem expressa na nota fiscal. Caso seja descumprido o prazo, o comprador está sujeito à multa e sanções penais. O órgão responsável para a fiscalização e certificação dos postos e unidades de recebimento das embalagens é o Instituto Nacional de Processamento de Embalagens Vazias (INPEV). Muito se tem feito neste sentido, como a utilização de campanhas na mídia, porém muitas regiões ainda não possuem postos aptos ao recebimento das embalagens, o que pode causar danos significativos ao ambiente, seja pela permanência das embalagens nas propriedades, seja pelo mau armazenamento em galpões não preparados, ou, ainda, o desvio destas embalagens para o mercado de falsificação (BRAGA; ROMANIELLO, 2008).

\section{MATERIAL E MÉTODOS}

A fazenda estudada está localizada na região de Monte Carmelo MG, município este que segundo IBGE (2009) possui uma área plantada de 13700 ha de lavoura de café, com uma produção média ano de $1800 \mathrm{~kg}$ de café em grão por ha. A fazenda produtora está em altitude de 900 metros. O período chuvoso da região ocorre no verão, já o inverno é seco e com temperatura que gira em torno de $25^{\circ} \mathrm{C}$. Este clima facilita a produção como um todo, tanto a produção quanto a colheita, assim à produção de cafés especiais, com sabor e aroma específico para o produto da região se torna mais fácil e acessível. Esta empresa agrícola possui uma área de 720.0 ha de terra onde 205 há são área de reserva e/ou APP (Área de Preservação Permanente), o restante da área destina-se à produção de café, plantado em linha e com espaçamentos que variam de acordo com a variedade plantada. 
Esta unidade conta com quinze funcionários fixos. Possuem dezesseis tratores cafeeiros, seis pulverizadores modelo jacto turbo que estão a disposição para a aplicação dos agroquímicos. A empresa conta ainda com três responsáveis direto de campo onde um cuida da parte de manejo integrado de pragas, doenças e aplicação dos defensivos, outro da parte operacional, como adubação acompanhamento da colheita, irrigação seca do café. E um terceiro agente que faz o acompanhamento geral da fazenda.

A fazenda possui uma área restrita onde são armazenadas as embalagens e manipulados os produtos, nesta instalação além de armazenar e manipular os produtos, os colaboradores tem vestiário com armários individuais. Nos mesmos são guardados os (EPI'S - Equipamento de Proteção Individual) e as pré roupas. Possui outro móvel onde são guardadas as roupas de uso diário, chuveiro para tomar banho, ducha de emergência, lava olhos e local para lavar os EPI'S.

As avaliações foram feitas pelo gerente da empresa. O mesmo tem como função analisar a aplicação de defensivos, supervisionar a regulagem e calibragem dos equipamentos, orientar quanto a área a ser aplicada os defensivos. Os funcionários que trabalham na seção de aplicação de agroquímicos possuem outras atividades além da pulverização, no momento em que não estão pulverizando, participou de outras atividades. Todos os colaboradores recebem treinamento para aplicação de agroquímicos e operadores de máquinas. O gerente sem que os operadores de máquinas soubessem que estavam sendo avaliados, colhia os dados e anotava na planilha de campo. A planilha verificou as condições do equipamento observando os vazamentos, os bicos, manômetro e filtro, as condições climáticas que avaliavam as condições do vento, a umidade relativa do ar e a temperatura, a tríplice lavagem da embalagem dos agrotóxicos e a armazenagem dos mesmos na embalagem de origem. Observou-se na planilha dos recursos humanos se a mão de obra possuía ou não treinamento, se o equipamento era devidamente regulado pelos aplicadores avaliando a posição dos bicos, a vazão e a velocidade de aplicação, se a empresa ofereceu e os 
funcionários faziam utilização dos equipamentos de proteção individual, avaliou a observação das recomendações técnicas, e se o trabalho realmente iniciava pelo supervisor. O resultado da pesquisa não sofreu interferência, no entanto os resultados são qualitativos, onde foi avaliada a qualidade da aplicação de agroquímicos.

Neste processo, foi acompanhada aplicações de agrotóxico na lavoura de café, onde foi observado e avaliado itens de controle. As notas foram distribuídas vão de zero a três, onde a nota zero é não conforme, um é não conforme maior, dois não conforme menor e três é conforme, posteriormente os resultados mostraram o grau de conformidade com as normas técnicas no uso destas substâncias. A avaliação foi realizada no ano de 2011, ano safra 2011/2012. A cada dois pulverizadores que saiam a campo para pulverizar neste período, um foi avaliado e anotado nestas planilhas, posteriormente tabulado e avaliado o nível de eficiência, para posterior análise e discussão. 0 modelo do questionário de campo segue anexo ao artigo e foi elaborado pelo próprio autor.

\section{RESULTADOS E DISCUSSÃO}

Os resultados obtidos na tabela 1 referente aos equipamentos utilizados na fazenda para a aplicação de agrotóxicos apresentam resultados satisfatórios atingem $85,38 \%$ dos equipamentos, mas deixam ainda algumas falhas, as mesmas não são consideradas graves, pois, o problema são apenas alguns defeitos nos equipamentos, defeitos estes que não interferem diretamente na aplicação dos agrotóxicos no campo. Os equipamentos com defeitos em sua maioria interferiam na facilidade de uso dos mesmos, itens como manômetro, bico utilizado para fazer a tríplice lavagem, anéis de vedação, que tornavam o trabalho mais difícil.

Em $88,89 \%$ dos questionários respondidos, o aplicador cumpriu com as precauções climáticas, foram aplicados os agrotóxicos somente quando as condições do tempo foram favoráveis, ou seja, os ventos estavam fracos, com 
temperaturas e umidades do ar amenas, para evitar que os agrotóxicos contaminassem áreas e canais entorno do campo.

A porcentagem de $11,11 \%$ apresenta certa deficiência na aplicação de agrotóxicos conforme as condições climáticas mostram que os funcionários utilizavam o produto em climas não favoráveis, ou seja, onda a temperatura e a velocidade do vento não condiziam com as normas gerais da aplicação, pois, o mesmos ao verificarem que ainda possuía produto no tanque, terminavam a aplicação mesmo sendo em condições climáticas não favoráveis. Caso não fosse aplicado o restante do produto poderia danificar o tanque e no dia seguinte o mesmo não teria a eficiência no combate a pragas e doenças.

É importante conhecer as condições climáticas para prever o comportamento dos herbicidas nas classes de solo e para seleção de dosagens adequadas, bem como para evitar efeitos prejudiciais ao ambiente e às culturas subseqüentes. (RESENDE et al., 2002)

A tríplice lavagem teve uma porcentagem suficiente atingiu $97,08 \%$, está bem próxmo de $100 \%$, mas, ainda é necessário um aperfeiçoamento na hora de destinar a central de recolhimento para reciclagem, existe um pouco de demora na devolução, os outros procedimentos são efetuados corretamente. Segundo Baptista (1996) a operação da tríplice-lavagem, além de ser extremamente simples, é também muito eficiente, com dados indicando $99,997 \%$ de remoção dos ingredientes ativos, transformando a embalagem de agrotóxico, antes considerada resíduo especial, em resíduos comuns passíveis de reciclagem. O armazenamento de agrotóxicos estava em conformidade atingiu $100 \%$, pois foi observado que os produtos estavam armazenados em suas embalagens de origem, dando uma segurança ao aplicador, oferecendo mais confiança em manipular os produtos e a fazenda não corre o risco de aplicar um produto inadequado.

Além da preocupação com a segurança da armazenagem do produto, a fazenda conta com uma construção que segue os padrões para armazenagem de produtos químicos, esta instalação ventilada e bem fechada, evitando assim a entrada animais e pessoas que não fazem parte do processo. 
Tabela 1: Verificação das condições de trabalho oferecidas pelo empregador na aplicação de agrotóxicos em uma fazenda em Monte Carmelo/MG no ano de 2011.

\begin{tabular}{|c|c|c|c|c|c|c|}
\hline \multicolumn{2}{|l|}{ Itens Avaliados } & 0 & 1 & 2 & 3 & $\%$ \\
\hline \multicolumn{2}{|l|}{$1^{\circ}$ Condições do } & 0 & 0 & 25 & $32(56 \%)$ & $85,38 \%$ \\
\hline \multicolumn{2}{|l|}{ equipamento } & $(0 \%)$ & $(0 \%)$ & $(44 \%)$ & & \\
\hline \multirow{2}{*}{\multicolumn{2}{|c|}{$2^{\circ}$ Condições Climáticas }} & 0 & 0 & 19 & $38(67 \%)$ & $88,89 \%$ \\
\hline & & $(0 \%)$ & $(0 \%)$ & $(33 \%)$ & & \\
\hline lavagem & da & 0 & 0 & $5(8 \%)$ & $52(92 \%)$ & $97,08 \%$ \\
\hline \multicolumn{2}{|l|}{ Embalagem } & $(0 \%)$ & $(0 \%)$ & & & \\
\hline Armazenagem & de & 0 & 0 & $0(0 \%)$ & $57(100 \%)$ & $100 \%$ \\
\hline \multicolumn{2}{|l|}{ Agrotóxicos } & $(0 \%)$ & (0\%) & & & \\
\hline
\end{tabular}

A qualidade da mão de obra, visualizada na tabela 2, demonstrou na pesquisa que 11 (onze) aplicadores, que corresponde a 19,3\%, não apresentavam o treinamento adequado que os prepararia para efetuar 0 serviço em que ali ocupavam o cargo, devido a baixa rotatividade de funcionários da empresa, o cronograma de treinamento contempla apenas um curso por ano, quando contratado o colaborador recebe apenas um preparamento informal de aplicações de agrotóxicos.

$\mathrm{Na}$ regulagem do equipamento os bicos foram o item que mais interferiram no resultado, em alguns momentos não apresentavam uniformidade de volume de pulverização, as posições não eram mudadas conforme o tamanho e a necessidade do produto na planta.

A fazenda ofereceu à sua mão de obra todos os EPI's (Equipamento de Proteção Individual), mas alguns trabalhadores, ou seja, 70,18\% efetuavam suas tarefas faltando equipamentos de proteção.

A falta de informação da maioria dos agricultores da necessidade de se utilizar equipamentos de proteção individual (EPI) é um fator de grave risco quando se trata do uso de agrotóxicos, principalmente no que diz respeito a 
intoxicações: impacto sobre a saúde pública, com sérios riscos de desenvolvimento de câncer e podendo levar à morte. A substância química, por si só, não é totalmente má ou boa. A caracterização do risco que ela representa será conseqüência do tipo de uso, da dose utilizada e da exposição a que um indivíduo é submetido, aliado à toxicidade inerente ao produto (KOTAKA; ZAMBRONE, 2001).

O processo da pulverização corresponde ao momento de maior utilização de normas de segurança individual; entretanto $80 \%$ dos indivíduos utilizam somente parcialmente o EPI. Esses porém, nem sempre são suficientes ou apropriados para a proteção contra os produtos utilizados, fato que confere com estudos realizados em países em desenvolvimento.

De acordo com o Censo Agropecuário do IBGE (Instituto Brasileiro de Geografia e Estatística) $56 \%$ das propriedades rurais do país, um total de 1,4 milhão, utilizam defensivos de forma inadequada.

Aplicações que não obedeçam às recomendações técnicas podem provocar danos às culturas suscetíveis do café, estas recomendações não foram totalmente feitas por parte dos trabalhadores, nem mesmo dos supervisores, algumas aplicações foram efetuadas sem os devidos cuidados.

A fazenda não apresentou conformidade na aplicação dos agrotóxicos, a mesma ofereceu os Equipamentos de Proteção Individual e os mesmos não foram utilizados, mas a fazenda errou pois ela tem a obrigação de oferecer e fiscalizar a utilização dos equipamentos, caso o gerente não consiga fiscalizar, é necessário que se contrate outra pessoa para observar e fazer cumprir a lei da utilização dos EPI's. Para que a recomendação técnica tenha um resultado satisfatório é necessário que os colaboradores sigam a risca todos os processos utilizados na aplicação, itens como condições climáticas, regulagem dos equipamentos, mão de obra qualificada, utilização correta dos EPI's, entre outros, interfere diretamente no resultado do item avaliado. 
Tabela 2: Condições relevantes do aplicador na aplicação de agrotóxicos numa fazenda em Monte Carmelo/MG no ano de 2011.

\begin{tabular}{lccccc}
\hline \multicolumn{1}{c}{ Itens Avaliados } & 0 & 1 & 2 & 3 & $\%$ \\
\hline 10 Qualidade da Mão de & 11 & 0 & 0 & 46 & $80,70 \%$ \\
Obra & $(19 \%)$ & $(0 \%)$ & $(0 \%)$ & $(81 \%)$ & \\
20 Regulagem do & 0 & 0 & 8 & 49 & $95,32 \%$ \\
Equipamento & $(0 \%)$ & $(0 \%)$ & $(14 \%)$ & $(86 \%)$ & \\
30 Utilização dos EPI's & 0 & 1 & 49 & 7 & $70,18 \%$ \\
& $(0 \%)$ & $(0 \%)$ & $(87 \%)$ & $(12 \%)$ & \\
40 Recomendação & 0 & 0 & 54 & $3(5 \%)$ & $68,42 \%$ \\
Técnica & $(0 \%)$ & $(0 \%)$ & $(95 \%)$ & & \\
50Trabalho Iniciou com & 0 & 0 & 4 & 53 & $97,66 \%$ \\
Supervisor & $(0 \%)$ & $(0 \%)$ & $(7 \%)$ & $(93 \%)$ & \\
60 Condições Saúde do & 0 & 0 & 0 & 57 & $100,00 \%$ \\
Aplicador & $(0 \%)$ & $(0 \%)$ & $(0 \%)$ & $(100 \%)$ & \\
\hline
\end{tabular}

\section{CONCLUSÃO}

A avaliação do grau de conformidade na aplicação de agrotóxicos em uma propriedade produtora de café em Monte Carmelo no ano de 2011, não mostrou resultado satisfatório. Mesmo a saúde dos aplicadores atingindo a conformidade de $100 \%$ não se pode tomar como garantia, pois este resultado era somente interrogativo e não resultado de avaliação clinica A mão de obra, os equipamentos, a utilização dos EPI's, as recomendações técnicas, a observação climática para aplicação dos agrotóxicos não atingiram a conformidade. Ambos os assuntos apresentaram problemas na execução das atividades, o que faz com que o ambiente e a saúde dos aplicadores sejam colocados em risco. Toda via devemos buscar acompanhar com maior atenção a execução deste tipo de trabalho, o grau de risco é muito grande e por isso 
LACERRA, A.L. e COSTA, C. Avaliação do grau de conformidade na aplicação de agrotóxicos em uma propriedade produtora de café em Monte Carmelo no ano de 2011. PUBVET, Londrina, V. 7, N. 17, Ed. 240, Art. 1586, Setembro, 2013.

outros trabalhos devem ser feitos para buscar resultados e soluções para 0 problema na aplicação de agrotóxico.

\section{REFERÊNCIAS}

BACHA, C. J. C. Economia e Política Agrícola no Brasil - São Paulo: Atlas, 2004.

BAPTISTA, G.C. DE. Descontaminação, reciclagem e descarte de embalagens de agrotóxicos. NOTESALQ, Ano IV. Abril /1996, número 10

BAUER, F.C.; PEREIRA, F. A. R. Fitossanidade e Produção Agrícola. In: BAUER, F. C.; VARGAS JUNIOR, F. M. Produção e Gestão Agroindustrial. Campo Grande: UNIDERP. 2005.

BRAGA JUNIOR, Walter; ROMANIELLO, Marcelo Márcio. Direito Ambiental: Percepção dos Agentes Envolvidos na destinação final das embalagens de agrotóxicos de acordo com a Lei $n^{\circ}$ 9.974/00, na região cafeeira do município de Lavras, no Sul de Minas Gerais. Universidade Municipal de São Caetano do Sul. Gestão \& Regionalidade, vol. 24, núm. 69, enero-abril, 2008

GARCIA, F. R.M. Zoologia Agrícola, Manejo Ecológico de Pragas. Porto Alegre: 2008.

GEREMIA, B. Agrotóxicos o emprego indiscriminado de produtos químicos no ambiente de trabalho rural e a responsabilização por danos à saúde. Dissertação (Mestrado) - Universidade Caxias do Sul. 2011.

INSTITUTO-UFRJ. Aplicação de agrotóxicos. Disponível em: <www.ufrrj.br./institutos/it/de/acidentes/aplic.htm>. Acesso em: 25 de maio de 2011.

KOTAKA, E. T.; ZAMBRONE, F. A. D. Contribuições para a Construção de Diretrizes de Avaliação do Risco Toxicológico de Agrotóxicos. Campinas, SP. 2001. 160p

LOPES, F.F.; CASTRO, L. T.; NEVES, M. F.; CALDEIRA, M. A.. O Vale do São Francisco: lições para o planejamento estratégico de uma região. In: NEVES, M. F. (coord.). Agronegócios e Desenvolvimento Sustentável: uma agenda para a liderança mundial na produção de alimentos e bioenergia. $1^{\text {a }}$ Edição. São Paulo: Atlas, 2008. Cap. 16, p. $128-138$.

LOURENÇO, J. C.. A evolução do Agronegócio Brasileiro no Cenário Atual. Dissertação. 2008

MACEDO, J.A.B. Introdução a Química Ambiental, Química \& Meio Ambiente \& Sociedade. $1^{\text {a }}$ edição. Editado pelo autor, 2002.

MACHADO, J. A. D.; OliveirA, L. M.; SCHNORRENBERGER, A.. Compreendendo a Tomada de Decisão do Produtor. 2006. 14 p. Dissertação (Mestrado Administração Rural) UFRGS, Porto Alegre, Rio Grande do Sul, 2006.

MACHADO, P. A. L. Direito Ambiental Brasileiro. Revista Atualizada e Ampliada. $11^{\text {a }}$ Edição. Editoração Eletrônica. Letra por letra Studio. São Paulo, 2003.

MARINO, M. K.; NEVES, M. F.; ROSSI, R. M.. Transformações na distribuição de insumos agrícolas no Brasil: um olhar para a frente. In: MARINO, M. K.; NEVES, M. F. (coord.). A 
revenda competitiva no agronegócio: Como melhorar sua rentabilidade. $1^{a}$ Edição.São Paulo. Editora Atlas, 2008. Capítulo 1. Pág. 03 - 11.

PESSANHA, B.M.R. O defensivo agrícola. In: Graziano Netto F. (org.). Uso de agrotóxicos e receituário agronômico. São Paulo: Agroedições, 1982.

POLASTRO, D. Estudo do caso de intoxicação ocasionado pelo uso de agrotóxicos no Estado do Paraná, durante o período de 1993 a 2000. Dissertação (Mestrado) 116p.

Escola Superior de Agricultura Luiz de Queirós, Piracicaba, 2005.

PORTO, Marcelo Firpo; SOARES, Wagner Lopes. Atividade agrícola e externalidade ambiental: uma análise a partir do uso de agrotóxicos no cerrado brasileiro.

Dissertação (Doutorado). Programa de Saúde Pública e Meio Ambiente da Escola Nacional de Saúde Pública. Ciência e Saúde Coletiva. 2007.

REDIVO, A. R.; SORNBERGER, A. R.; SORNBERGER, G. P.. Desenvolvimento Sustentável: Um Estudo Bibliográfico no Caso da Soja na Região do Estudo do Mato Grosso.

Disponível em: <www.ceplac.gov.br/radar/Artigos/artigos1.htm>. Acesso em: 19 de setembro 2011. Rural. Porto Alegre: UFRGS, 2006.

ReSEnde, M.; CURI, N.; REZENDE, S. B. DE.; CORRÊA, G. F.. Pedologia: base para distinção de ambientes. $4^{\mathrm{a}}$ Ed. Viçosa: NEPTU, 2002.

SANTINATO,R.; FERNANDES, A.L.T.; FERNANDES, D.R..Irrigação na Cultura do Café. $2^{a}$ Ed. Belo Horizonte: Editora O Lutador, 2008.

SANTINATO,R.; FERNANDES, A.L.T.; .Cultivo do Cafeeiro Irrigado por Gotejamento. Belo Horizonte: Editora O Lutador, 2005. 257 p.

VIEIRA, W. C. (Ed.). Agricultura na virada do milênio: velhos e noves desafios. Viçosa, 2000. p. $93-116$

ZAMBRONE, F.A.D. Defensivos agrícolas ou agrotóxicos? Perigosa família. Ciência Hoje, 1986. 22: 44.47 . 